\title{
Screening of novel immunostimulatory CpG ODNs and their anti-leukemic effects as immunoadjuvants of tumor vaccines in murine acute lymphoblastic leukemia
}

\author{
JIN WANG, WANGGANG ZHANG, AILI HE, WANHONG ZHAO and XINGMEI CAO \\ Department of Hematology, Second Affiliated Hospital, Medical School of \\ Xi'an Jiaotong University, Xi'an 710004, Shaanxi Province, P.R. China
}

Received July 29, 2010; Accepted October 11, 2010

DOI: $10.3892 /$ or.2010.1093

\begin{abstract}
Acute lymphoblastic leukemia (ALL) is a common malignant disease and a major cause of mortality due to recurrent disease. Immunotherapy is a promising strategy for eradicating minimal residual disease and thus preventing the relapse of leukemia. Apart from stem cell transplantation, $\mathrm{CpG}$ oligodeoxynucleotides (ODNs) are excellent candidates for the immunotherapy of leukemia. However, the number of usable CpG ODNs is limited. In this study, we tested a panel of $\mathrm{CpG}$ ODNs and obtained three $\mathrm{CpG}$ ODN sequences with strong immunostimulatory activity by comparing their capacity to activate lymphocytes. The data revealed that the flanking bases, the spacing of individual $\mathrm{CpG}$ motifs and polyguanosine ends, contribute to the immunostimulatory activity of a CpG ODN. In the immunotherapy of murine leukemia with the novel ODN as the adjuvant, we found that $\mathrm{CpG}$ Seqs 14 and 19 were effective in the treatment of a leukemia model by prolonging survival span, augmenting natural killer cell and CTL cytotoxicity, as well as increasing the number of long-term survivors. The ability of CpG ODN to induce both strong innate and adaptive anti-leukemic immune activity could render it an appropriate agent for therapeutic applications in acute leukemia. This study demonstrates the feasibility of active immunotherapy with $\mathrm{CpG}$ ODNs in patients with acute leukemia and thus represents a potential alternative therapeutic strategy for eradicating residual disease which is resistant to conventional cytoreductive treatment.
\end{abstract}

\section{Introduction}

Despite intensive chemotherapy regimens, long-term survival occurs in only a third of cases of adult acute leukemia.

Correspondence to: Dr Wanggang Zhang, Department of Hematology, Second Affiliated Hospital Medical School of Xi'an Jiaotong University, 157 Xiwu Road, Xincheng District, Xi'an 710004, Shaanxi Province, P.R. China

E-mail: blankeyes8182@gmail.com

Key words: $\mathrm{CpG}$ oligodeoxynucleotides, toll-like receptor, immunotherapy, tumor vaccine, acute leukemia
Additional therapeutic strategies are required in order to further prolong remission duration and eradicate minimal residual disease, ideally with less toxicity than conventional chemotherapy. One of the these approaches is active immunotherapy with novel vaccination regimens. We previously launched a phase-I clinical trial and evaluated the efficacy and toxicity of vaccination in patients with relapsed or refractory acute leukemia, which proved to be a feasible, safe, and capable way of eliciting anti-leukemic responses in vivo (1).

As tumor cells are considered to be poorly immunogenic, it is difficult to elicit an effective specific anti-tumor activity from these cells alone. In addition, tumor cells develop various immune mechanisms to escape from host immune surveillance, for example, down-regulating co-stimulatory signals essential for the activation of the immune system. An appropriate adjuvant could help break the immune tolerance in acute leukemia patients. To that end, tumor antigens need to be administered in combination with adjuvants. The most common adjuvant used so far in experimental models is Incomplete Freund's adjuvant (IFA). IFA has also been successfully used in human immunotherapy against melanoma involving gp 100 peptide immunization (2). However, it is not widely used in human vaccination protocols due to its undesirable severe side-effects, which include swelling and indurations at the injection site. IFA has also been reported to induce specific CTL tolerance as opposed to immunity against immunizing antigens (3). Cytokines, such as interleukin (IL)-2, are another type of adjuvant being increasingly used in hematological malignant disease. However, systemic therapy with cytokines is also associated with severe toxic side effects, including wheezing and difficulty in breathing, dizziness when changing position, rapid weight gain or sudden swelling, chest pain or irregular heartbeat, and so on. For these reasons, alternative potent and safe adjuvants need to be identified.

In the last few years, a type of synthetic oligonucleotide containing unmethylated cytosine and guanine dinucleotides within specific-sequence contexts ( $\mathrm{CpG}$ motifs), has been shown to provoke strong immune responses (4) as well as remarkable $\mathrm{T}$ cell-dependent anti-tumor efficacy in a series of murine tumor models. CpG oligodeoxynucleotides (ODNs) are thought to mimic bacterial DNA and are recognized as a 'danger' signal by the innate immune system of mammals. 
As toll-like receptor (TLR) 9 agonists, CpG ODNs boost innate immunocytes such as B-cells, dendritic and natural killer (NK) cells, as well as monocytes, causing them to proliferate, mature and produce various cytokines, including IL-6, and -12, tumor necrosis factor (TNF) and interferon (5). In addition, CpG ODN stimulation leads to the generation of Th1 type adaptive immune responses (6-8). These properties have led to considerable interest in the clinical use of CpG ODNs in vaccines, cancer and autoimmune disease therapy (9).

Despite these promising benefits of $\mathrm{CpG}$ ODNs, the numbers of usable $\mathrm{CpG}$ ODNs are limited in the current clinical setting of cancer immunotherapeutics. The clinical restriction of $\mathrm{CpG}$ ODNs is due to several reasons: The absence of convenient screening assays, difficulty to predict the structure of potent $\mathrm{CpG}$ ODNs and the differences between species of $\mathrm{CpG}$ motif recognition (10). While the primary focus for the medicinal application of $\mathrm{CpG}$ ODNs has been on cancer immunotherapy in pre-clinical and clinical trials against cancer (11-14), there have been no reports of the in vivo consequences of the immunotherapeutic effects of CpG ODN treatment as adjuvants in acute leukemia. In this study, in order to develop CpG ODNs for clinical use, we designed a panel of CpG ODNs (Table I) with different structural features following the characteristics which contribute to the potency of a human CpG ODN (15). We then compared their ability to induce cell proliferation and cytokine secretion, and selected the most potent ODN. Finally, we observed the treatment effect of vaccines with the formulation of a $\mathrm{CpG}$ ODN adjuvant and their ability to elicit anti-leukemic immune responses in a mouse model.

\section{Materials and methods}

Mice. Six-week-old female Balb/c mice were purchased from the Laboratory Animal Center, Medical Shcool of Xi'an Jiaotong University. Female DBA/2 mice between 4 and 6 weeks of age were purchased from the Shanghai Laboratory Animal Center after approval by the Chinese Academy of Sciences. The animals were housed in a specific pathogenfree animal facility under isothermal conditions and were allowed access to food and water ad libitum.

Leukemia cell line and cell culture. L1210, which is a murine lymphoid leukemia cell line of DBA/2 origin, was a generous gift from Professor Yili Wang (Institute for Cancer Research, College of Life Science and Technology, Xi'an Jiaotong University, China) and was maintained in RPMI-1640 (Gibco, BRL, Gaithersburg, MD, USA) supplemented with $10 \%$ heat-inactivated fetal bovine serum, $100 \mathrm{U} / \mathrm{ml}$ penicillin, and $100 \mu \mathrm{g} / \mathrm{ml}$ streptomycin at $37^{\circ} \mathrm{C}$ in a humidified atmosphere of $5 \% \mathrm{CO}_{2}$.

$C p G O D N$. CpG ODN were synthesized and purified by the Coley Pharmaceutical Group (San Diego, USA) under good manufacturing practice conditions. The sterile, endotoxin-free solution of CpG ODN was supplied in vials containing $1 \mathrm{mg}$ in $1 \mathrm{ml} \mathrm{TE}$ buffer and stored at $-20^{\circ} \mathrm{C}$. For future use, $\mathrm{CpG}$ ODN was further reconstituted in sterile PBS (0.1 M PBS, $\mathrm{pH} 7.2$ ) at a concentration of $500 \mu \mathrm{g} / \mathrm{ml}$ and stored at $4^{\circ} \mathrm{C}$. All dilutions were conducted using pyrogen-free reagents.
The sequences of CpG ODN used in this study are described in Table I.

The in vitro study

Cell preparation and culture. Human peripheral blood mononuclear cells (PBMCs) were collected and isolated from the peripheral blood of healthy volunteers by Ficoll-Paque density gradient centrifugation (Histopaque-1077, SigmaAldrich, St. Louis, MO, USA) as previously described (16), after receiving approval from the Institute for Cancer Research, College of Life Science and Technology, Xi'an Jiaotong University. Cells were suspended in RPMI-1640 culture medium supplemented with $10 \%(\mathrm{v} / \mathrm{v})$ heat-inactivated $\left(56^{\circ} \mathrm{C}, 30 \mathrm{~min}\right)$ fetal bovine serum, $100 \mathrm{U} / \mathrm{ml}$ penicillin, and $100 \mu \mathrm{g} / \mathrm{ml}$ streptomycin (all from Life Technologies, Grand Island, NY). All compounds were purchased endotoxintested. Viability was determined before and after incubation with ODN by trypan blue exclusion (conventional microscopy). In all experiments, $>95 \%$ of PBMCs were viable. The cells (final concentration, $2.5 \times 10^{6}$ cells $/ \mathrm{ml}$ ) were then cultured in complete medium in a $5 \% \mathrm{CO}_{2}$-humidified incubator at $37^{\circ} \mathrm{C}$ for $48 \mathrm{~h}$. Different ODNs (Table I; final concentration, $1 \mu \mathrm{g} / \mathrm{ml}$ ) and LPS (from Salmonella typhimurium; Sigma Aldrich) were used as stimuli.

Spleens were removed from 6-week-old female Balb/c mice, dispersed and centrifuged at 1,000 rpm for $5 \mathrm{~min}$. The supernatant was removed and the cell pellet was re-suspended in $0.84 \% \mathrm{NH}_{4} \mathrm{Cl}$ to eliminate red blood cells. Cells were washed twice with RPMI-1640 medium, re-suspended in the culture medium and cultured at $5 \times 10^{6} / \mathrm{ml}$ with the different ODNs.

Cell proliferation assay. The proliferation of human PBMCs and mice splenocytes was assessed by the quantitative assay, Cell Counting Kit-8 (CCK-8) (Dojindo, Gaithersburg, MD) according to the manufacturer's instructions. Briefly, this cell-counting method is an optical density colorimetric assay that quantifies the number of viable cells per well based on the activity of cellular dehydrogenases. At 44 h, $20 \mu \mathrm{l} /$ well CCK-8 were added to the medium and cultured together for $4 \mathrm{~h}$, and then the absorbance at $450 \mathrm{~nm}$ was determined.

Detection of cytokines. PBMCs and mouse splenocytes were plated in $24-$ well dishes using $2.5 \times 10^{6}$ or $5 \times 10^{6}$ cells $/ \mathrm{ml}$, respectively. The $\mathrm{CpG}$ ODNs were added to the cell cultures at a final concentration of $1 \mu \mathrm{g} / \mathrm{ml}$. The cells were then incubated at $37^{\circ} \mathrm{C}$ for $24 \mathrm{~h}$ and the supernatants were collected for ELISA assays. The experiments were performed twice for each CpG ODN in triplicate. The secretion of IL-6 and -12 p70 was measured by ELISA according to the manufacturer's instructions. The required reagents, including cytokine antibodies and standards, were purchased from PharMingen.

\section{The in vivo study}

Leukemia model. DBA/2 mice received live L1210 cells on day 0 by intraperitoneal (i.p.) injection. The cell dose was $1 \times 10^{5}$ cells per mouse. Cells were diluted in $200 \mu 1$ of PBS before injection. We then divided the animals into 7 groups, 10 mice in each. All treatments were initiated the following day. 
Table I. The CpG ODN panel used.

\begin{tabular}{|c|c|c|}
\hline ODN & Sequence (5' to $\left.3^{\prime}\right)$ & Length \\
\hline 1826 & TCCATGAㅌGTTCCTGAㅌTT & 20 mer \\
\hline 2006 & 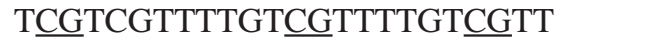 & 24 mer \\
\hline CpG 2006GC (2137) & TGCTGCTTTTGTGCTTTTGTGCTT & 24 mer \\
\hline CpG 1826GC (2138) & TCCATGAGCTTCCTGAGCTT & 20 mer \\
\hline CpG Seq 1 & 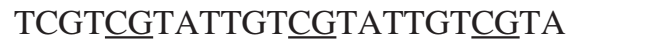 & 24 mer \\
\hline CpG Seq 2 & TCGTCGTTTTGTCGTATTGTCGTA & 24 mer \\
\hline CpG Seq 3 & TCGTCGTTTTGTEGTTTTGTCGTA & 24 mer \\
\hline CpG Seq 4 & TCGTEGTCTTGTGTCTTGTGTC & 24 mer \\
\hline CpG Seq 5 & TCGTCGTTTTGTEGTCTTGTCGTC & 24 mer \\
\hline CpG Seq 6 & TCGTCGTTTTGTEGTTTTGTEGTC & 24 mer \\
\hline CpG Seq 7 & TCGTCGTTTTGTEGTCTTGTCGTA & 24 mer \\
\hline CpG Seq 10 & TCGTCGTTGTEGTT & 14 mer \\
\hline CpG Seq 11 & 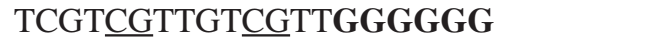 & 20 mer \\
\hline CpG Seq 12 & TCGTGTTGTGTTGTGTTGGGGGG & 26 mer \\
\hline CpG Seq 13 & 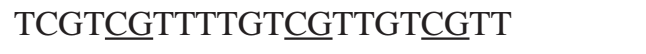 & 22 mer \\
\hline CpG Seq 14 & TCGTCGTTTTGTCGTTTGTCGTT & 23 mer \\
\hline CpG Seq 15 & 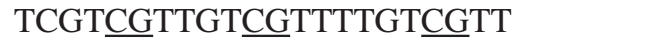 & 22 mer \\
\hline CpG Seq 16 & 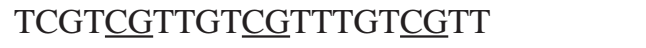 & 21 mer \\
\hline CpG Seq 17 & 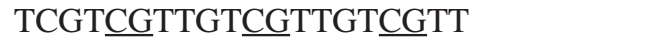 & 20 mer \\
\hline CpG Seq 18 & 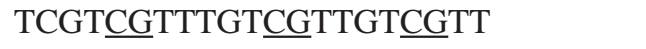 & 21 mer \\
\hline CpG Seq 19 & TCGTCGTTTGTEGTTTGTEGTT & 22 mer \\
\hline CpG Seq 20 & 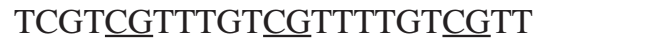 & 23 mer \\
\hline
\end{tabular}

CG dinucleotides are underlined. Poly G motifs are in bold letters. All sequences are synthesized with a wholly phosphorothioate backbone.

Table II. Vaccine formulation of each group.

\begin{tabular}{ll}
\hline Group & \multicolumn{1}{c}{ Vaccine formulation } \\
\hline Control & PBS solution \\
Single & Inactivated L1210 \\
Non-CpG & Inactivated L1210 + CpG 1826GC \\
& or CpG 2006GC \\
1826 & Inactivated L1210 + CpG 1826 \\
2006 & Inactivated L1210 + CpG 2006 \\
Seq 14 & Inactivated L1210 + CpG Seq 14 \\
Seq 19 & Inactivated L1210 + CpG Seq 19 \\
\hline
\end{tabular}

Vaccines were prepared as described in Materials and methods.

Vaccine preparation. Live L1210 cells were conditioned with $60 \mu \mathrm{g} / \mathrm{ml}$ of mitomycin $\mathrm{C}$ (Sigma) at $37^{\circ} \mathrm{C}$ for $30 \mathrm{~min}$. CpG ODN (50 $\mu \mathrm{g}, 0.1 \mathrm{ml})$ was then added into the inactivated L1210 cells ( $1 \times 10^{5}$ cells, $\left.0.1 \mathrm{ml}\right)$. The volume of all vaccine injections was $200 \mu 1$.

Therapeutics. Mice received the vaccines by subcutaneous injection on days $1,4,7,10$ and 14 after the i.p. inoculation of live L1210 cells. The vaccine formulation is shown in Table II. The animals were observed daily for survival for a minimum of 60 days.

Cytotoxicity assays of CTL and NK cells. At 14 days after inoculation, spleens from the tumor-bearing mice were collected and single-cell suspensions were prepared in order to test CTL activity and NK cytotoxicity. The erythrocytes were depleted with ammonium chloride lysis buffer. The cells were directly used as NK effector cells. For the preparation of CTL effector cells, splenocytes $\left(5 \times 10^{6}\right)$ were co-cultured with inactivated L1210 cells $\left(1 \times 10^{6}\right)$ in $5 \mathrm{ml}$ RPMI-1640 for 5 days in the presence of recombinant IL-2 $(20 \mathrm{U} / \mathrm{ml})$ and were then harvested as CTL effector cells. The CTL and NK cytotoxicities were determined using the CytoTox 96 assay kit (Promega, Madison, WI, USA) following the manufacturer's instructions. L1210 and YAC-1 cells were used as the target cells for the CTL and NK cytotoxicity, respectively, and were seeded into the microtiter plate at various effector to target $(\mathrm{E} / \mathrm{T})$ ratios. The amount of lactate dehydrogenase $(\mathrm{LDH})$ released in the culture supernatant was then measured, and the percentage of cytotoxicity was calculated according to the following formula: \% of specific lysis $=[($ experimental LDH release-spontaneous LDH release)/(maximum LDH release-spontaneous LDH release)] x 100 . 
A

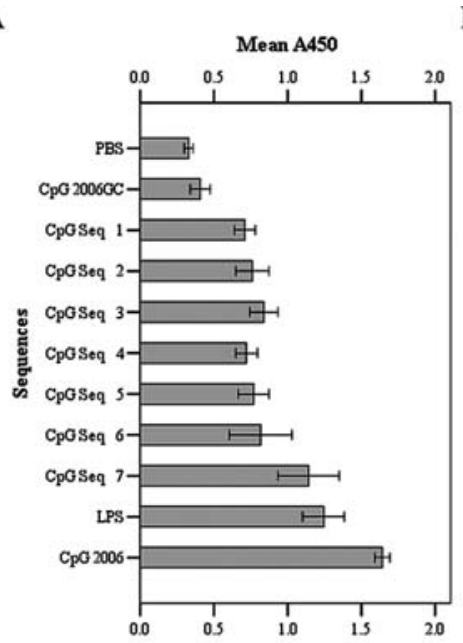

B

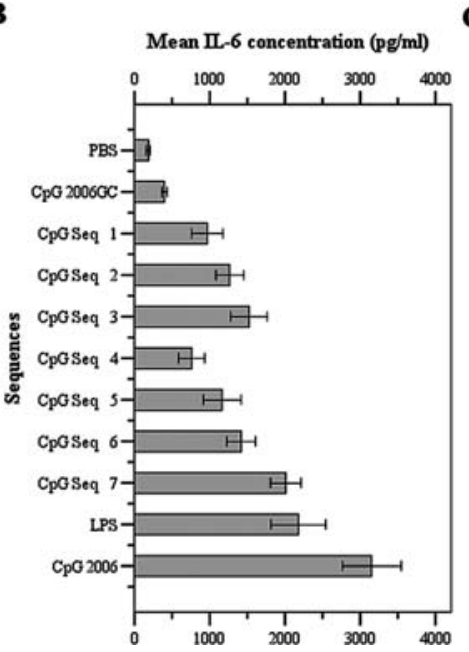

$\mathbf{C}$

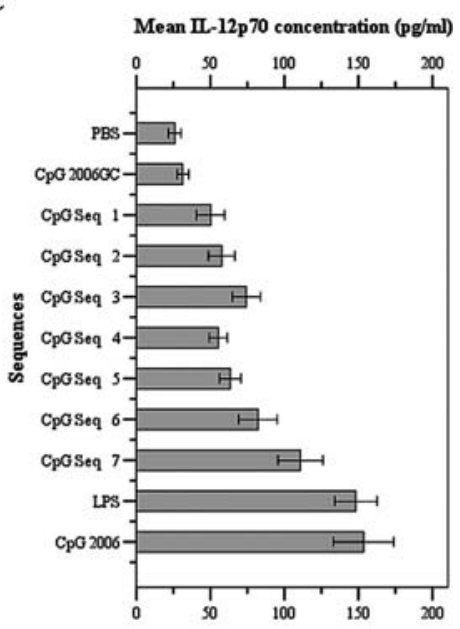

Figure 1. Effect of 3'-flanking bases of the CpG motif on the stimulatory activity of an ODN. (A) PBMCs were assayed for proliferation in response to the indicated ODN. Human PBMCs were incubated with ODN $(1 \mu \mathrm{g} / \mathrm{ml})$ with the sequences indicated in Table I. (B) IL- 6 was determined in the supernatant. (C) PBMCs were stimulated and IL-12p70 was determined. Shown are the mean values and standard deviations from three independent experiments.

Statistical analysis. Data were expressed as the means \pm SD. The two-tailed Student's t-test was used for a two-group comparison. For a comparison of more than two groups the Kruskal-Wallis test (ANOVA) was used. Survival curves were plotted using Kaplan-Meier estimates. The log-rank test was used to analyze survival data. Statistical significance was set at $<0.01$. All statistical tests were performed using SPSS 15.

\section{Results}

Differential immune activities of $C p G$ ODN with different structural characteristics. The $\mathrm{CpG}$ motif is the essential element for the immunostimulation of bacterial DNA and synthetic ODNs. Other factors also contribute to the activity of CpG ODN, such as flanking bases, spacing, poly-guanosine (poly G) ends, length, number of $\mathrm{CpG}$ motifs, and so on. In this study, we examined a panel of synthetic B-class ODNs in order to investigate their structure-activity relationship.

In order to evaluate the impact of flanking bases on activity, we progressively replaced part or all of $3^{\prime} \mathrm{TpT}$ with $3^{\prime} \mathrm{TpA}$ or $3^{\prime} \mathrm{TpC}$, and tested its ability to stimulate human PBMCs. The data indicate that substituting TpA (CpG Seqs $1-3$ vs. $\mathrm{CpG} 2006, \mathrm{P}<0.01)$ or $\mathrm{TpC}(\mathrm{CpG}$ Seqs $4-6$ vs. $\mathrm{CpG}$ $2006, \mathrm{P}<0.01$ ) for $3^{\prime} \mathrm{TpT}$ reduces ODN activity (Fig 1 ). In addition, there was no significant difference between $3^{\prime} \mathrm{TpA}$ and $3^{\prime} \mathrm{TpC}$ in stimulating activity (CpG Seq 1 vs. CpG Seq 4, CpG Seq 2 vs. CpG Seq 5, CpG Seq 3 vs. CpG Seq 6, $\mathrm{P}>0.01$ ). Furthermore, the immunostimulating activity of CpG ODN decreased with the increment of substitution. For example, the activity of CpG Seq 1 and 4, with all of 3'TpT in the sequence replaced, was slightly lower than that of $\mathrm{CpG}$ Seq 2, 3, 5 and $6(\mathrm{P}<0.01)$. However, it should be noted that the activity of $\mathrm{CpG}$ Seq 7 with all of 3'TpT replaced in the sequence, was stronger than that of both CpG Seq 1 and 4 with the same level of substitution $(\mathrm{P}<0.01)$.

An important question is whether the immune effects of $\mathrm{CpG}$ motifs can be modified by the presence of other types of sequence motifs. Poly G runs consisting of 4-6 Gs, have previously been reported to increase the immunostimulatory activity of phosphodiester ODNs (PE ODNs) (17-19). In order to analyze the effects of poly $\mathrm{G}$ strings on phosphorothioate ODNs (PTO-ODNs), CpG Seq 11 and 12, each of which contained a 3 '-end poly $\mathrm{G}$ addition, were examined by proliferation assay and cytokine secretion (Fig. 2). The results showed that the 3'-end poly $\mathrm{G}$ addition did not enhance the activity of $\mathrm{CpG}$ Seq 11 (vs. CpG Seq 10, P>0.01). As for CpG Seq 12, the 3'-end poly G sequence addition greatly reduced the ability to induce cell proliferation and IL-6 secretion (vs. CpG Seq 17, P<0.01).

The spacing between single motifs is also critical, and the separation by $\mathrm{TpT}$ was preferable (CpG 2006) (15). However, the importance of isolated $\mathrm{T}$ spacing within $\mathrm{CpG}$ ODNs has not yet been studied in detail. Therefore, in this study, we designed a panel of $\mathrm{CpG}$ ODNs with different $\mathrm{T}$ spacing sequences. As shown in Fig. 3, CpG Seq 13 and 14, with T spacing adjacent to the 3 '-end partly deleted, were not significantly different from $\mathrm{CpG} 2006(\mathrm{P}>0.01)$ concerning PBMC proliferation and IL-6 and IL-12p70 secretion. However, the immunostimulatory activity of CpG Seq 15 and 20, with the $\mathrm{T}$ spacing adjacent to the 5 '-end deleted, was greatly decreased (vs. CpG 2006, P<0.01). CpG Seqs 16-19, whose 5'- and 3'-end T spacings were both changed, showed significantly decreased activity (vs. CpG 2006, P<0.01), except for CpG Seq 19. The immunostimulatory activity of CpG Seq 13, 14 and 19 was significantly higher than that of other ODNs, and was equivalent to that of $\mathrm{CpG} 2006$ ( $\mathrm{P}>0.01$ ).

Screening of a panel of ODNs for most potent sequences. Previous studies have demonstrated that in vitro assays for PBMC activation, and the production of IL-6 and -12, could provide valuable information in vitro to predict the adjuvant activity of a given ODN in vivo (15). Based on these results, we screened a panel of CpG ODNs by comparing their ability to induce the proliferation of PBMCs and the production of IL-6 and IL-12p70, in order to find the most potent sequence for tumor vaccination.

As further statistical analysis showed (Table III), CpG Seqs 13,14 , and 19 , were much more potent than other 
$\mathbf{A}$

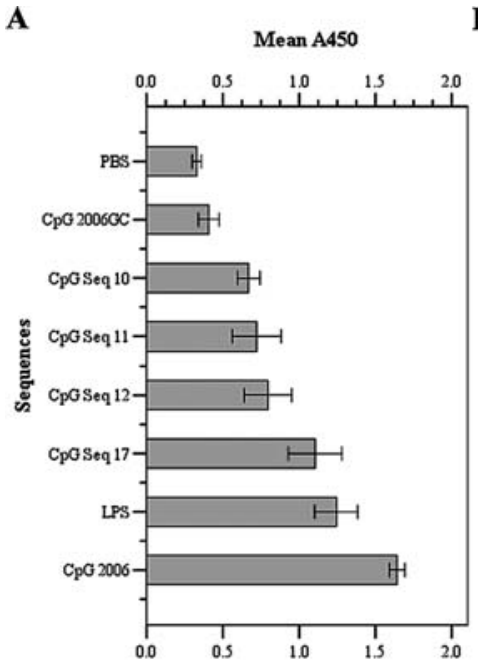

B

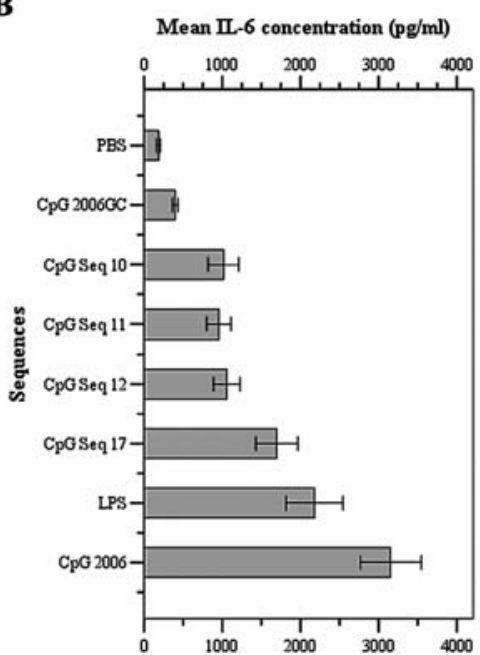

C

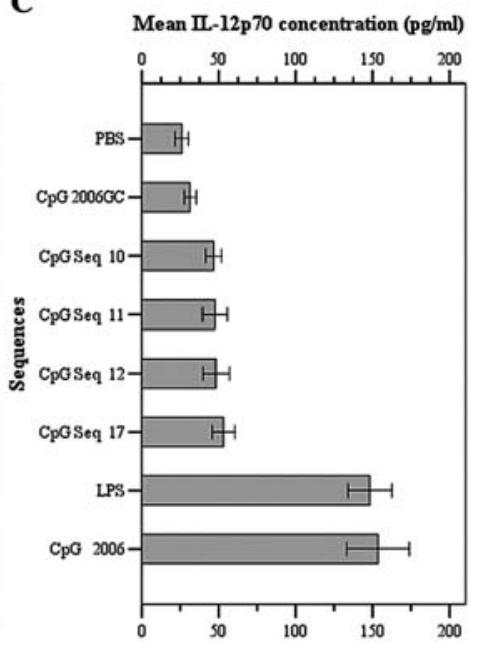

Figure 2. The 3'-end poly G addition cannot increase the immunostimulative capacity of CpG ODNs which are completely phosphorothioate-modified. Shown are the mean values and standard deviations from three independent experiments.

$\mathbf{A}$

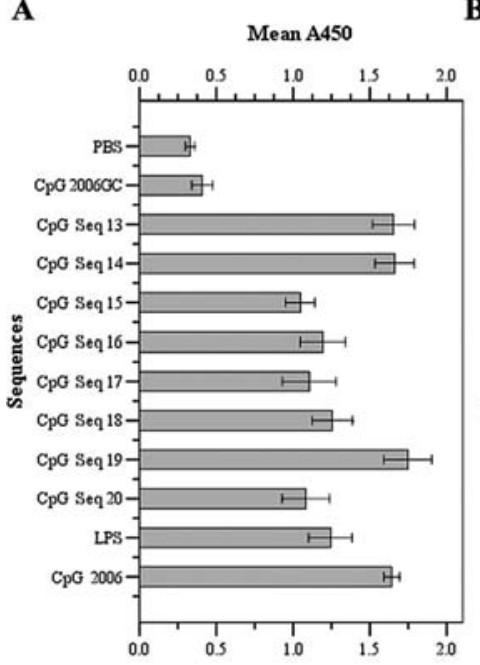

B

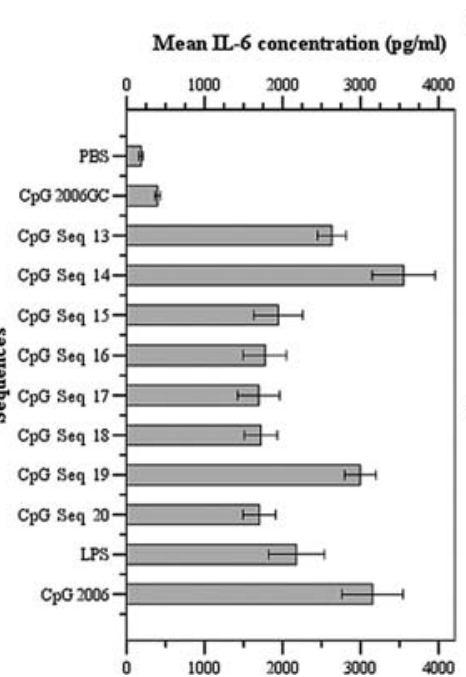

C

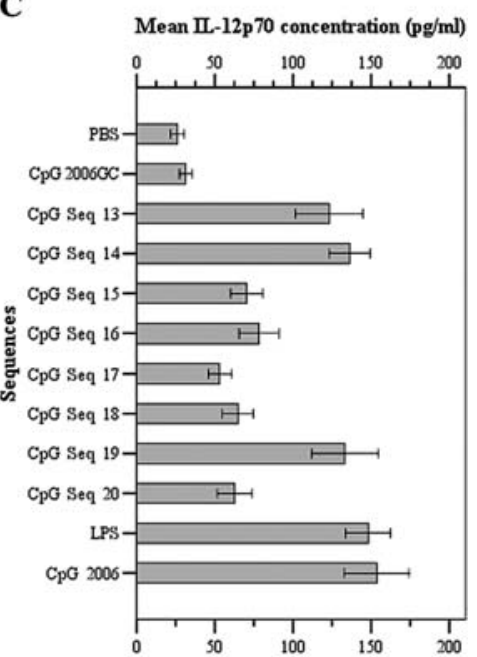

Figure 3. Effect of T spacing sequences on the stimulatory activity of CpG ODNs.

ODNs $(\mathrm{P}<0.01)$. The maximum responses of $\mathrm{CpG}$ Seqs 14 and 19 were up to $93.4435 \pm 9.8247$ and $89.1638 \pm 12.2184 \%$, respectively, almost equal to those of $\mathrm{CpG} 2006$ (P>0.01). In addition, there was no significant difference between $\mathrm{CpG}$ Seq 14 and 19. Moreover, CpG Seq 13 was a potent inducer of immunostimulation, and the maximum response was up to $80.7241 \pm 12.9917 \%$. However, this ODN was slightly less active than CpG Seqs 14 and 19, and CpG 2006 as well $(\mathrm{P}<0.01)$. In this primary screening, we obtained three B-class ODNs with strong immunostimulatory activity, Seqs 13, 14 and 19.

In vitro mouse splenocyte proliferation and cytokine secretion. Previous studies have demonstrated that $\mathrm{CpG}$ ODNs are effective vaccine adjuvants in mice $(6,20-23)$. However, these mice stimulatory ODNs have shown more modest effects on human leukocytes (24). Due to the evolutionary divergence of TLR9 in CpG recognition between species, the precise sequence motif that is optimal for stimulating immune cells of one species frequently differs from that which is optimal for stimulating cells of other species. In order to develop potent $\mathrm{CpG}$ ODNs for both humans and mice, we examined the immunostimulatory effect of the three sequences on mouse splenocytes. As seen in Fig. 4, CpG 1826, containing three '5'-GACGTT-3' motifs, showed the highest activity in inducing splenocyte proliferation and cytokine secretion $(\mathrm{P}<0.01)$. In inducing IL-6 secretion, $\mathrm{CpG} 1826$ showed activity as high as $1301 \pm 110 \mathrm{pg} / \mathrm{ml}$ of IL-6. CpG Seqs 13,14 and 19 showed similar activity as CpG 2006 in splenocyte proliferation $(\mathrm{P}>0.01)$, while a little lower in IL-6 secretion $(\mathrm{P}>0.01)$. However, $\mathrm{CpG}$ Seq 19 induced a markedly higher concentration of IL-12p70 compared to $\mathrm{CpG} 2006$ ( $\mathrm{P}<0.01)$, while CpG Seq 13 and 14 showed the same activity with it (P>0.01). On the whole, CpG Seqs 13, 14 and 19 showed strong immune activity in both humans and mice in vitro $(\mathrm{P}<0.01)$. 
Table III. Screening for the most potent phosphorothioate ODN sequences for the activation of human PBMCs.

\begin{tabular}{llccc}
\hline & \multicolumn{4}{c}{$\%$ Maximim response } \\
\cline { 2 - 5 } ODN & Proliferation & IL-6 & IL-12 & Average \\
\hline CpG Seq 1 & $26.9445 \pm 4.3373$ & $23.1652 \pm 5.3144$ & $19.0271 \pm 6.4525$ & $23.0456 \pm 5.8253$ \\
CpG Seq 2 & $30.3364 \pm 6.8520$ & $32.1631 \pm 4.7968$ & $24.6947 \pm 6.0327$ & $29.0647 \pm 6.1609$ \\
CpG Seq 3 & $35.9401 \pm 5.7023$ & $39.8247 \pm 6.2803$ & $37.6304 \pm 6.4072$ & $37.7984 \pm 5.5766$ \\
CpG Seq 4 & $27.6426 \pm 4.5795$ & $17.1290 \pm 4.3516$ & $22.8613 \pm 4.2521$ & $22.5443 \pm 5.9396$ \\
CpG Seq 5 & $31.1050 \pm 6.4246$ & $29.1197 \pm 6.3342$ & $29.2978 \pm 4.7604$ & $29.8408 \pm 5.1884$ \\
CpG Seq 6 & $34.4263 \pm 13.0492$ & $36.6879 \pm 4.9666$ & $44.0539 \pm 8.7219$ & $38.3894 \pm 9.3146$ \\
CpG Seq 7 & $57.3490 \pm 12.5061$ & $54.2744 \pm 5.2660$ & $66.3868 \pm 10.2786$ & $59.3367 \pm 10.1082$ \\
CpG Seq 10 & $24.0016 \pm 4.4947$ & $24.6940 \pm 5.0527$ & $16.0821 \pm 3.3152$ & $21.5926 \pm 5.5992$ \\
CpG Seq 11 & $27.7249 \pm 9.8238$ & $22.9662 \pm 3.9966$ & $16.7804 \pm 5.5606$ & $22.4905 \pm 7.6443$ \\
CpG Seq 12 & $32.8397 \pm 9.5352$ & $25.9957 \pm 4.3898$ & $17.1963 \pm 5.8695$ & $25.3439 \pm 9.0710$ \\
CpG Seq 13 & $93.4208 \pm 8.2751$ & $72.6642 \pm 4.6764$ & $76.0874 \pm 14.6044$ & $80.7241 \pm 12.9917^{\mathrm{a}}$ \\
CpG Seq 14 & $93.9097 \pm 7.7033$ & $100.0000 \pm 10.2961$ & $86.4208 \pm 9.0534$ & $93.4435 \pm 9.8247^{\mathrm{a}}$ \\
CpG Seq 15 & $50.7604 \pm 5.8223$ & $52.2112 \pm 7.9964$ & $34.7457 \pm 6.9168$ & $45.9058 \pm 10.3380$ \\
CpG Seq 16 & $61.0089 \pm 9.0953$ & $47.3018 \pm 7.1550$ & $40.8840 \pm 8.6249$ & $49.7316 \pm 11.4602$ \\
CpG Seq 17 & $54.7235 \pm 10.7053$ & $44.8600 \pm 6.8943$ & $21.1272 \pm 4.9834$ & $40.2369 \pm 16.4437$ \\
CpG Seq 18 & $65.3080 \pm 8.1215$ & $45.6322 \pm 5.4850$ & $30.3648 \pm 6.7056$ & $47.1017 \pm 16.2914$ \\
CpG Seq 19 & $99.9976 \pm 9.6790$ & $83.4871 \pm 5.1268$ & $84.0068 \pm 14.5911$ & $89.1638 \pm 12.2184^{\mathrm{a}}$ \\
CpG Seq 20 & $53.2120 \pm 9.4316$ & $45.0847 \pm 5.4055$ & $28.6858 \pm 7.5261$ & $42.3275 \pm 12.6795$ \\
CpG 2006 & $92.5346 \pm 3.1045$ & $88.1764 \pm 10.1051$ & $100.0000 \pm 13.9353$ & $93.5703 \pm 10.1637$ \\
\hline
\end{tabular}

The level of immunostimulatory activity induced by $1 \mu \mathrm{g} / \mathrm{ml}$ of 18 different ODNs was monitored in PBMCs from three donors. In order to facilitate the comparison between donors, the maximum response in each assay was set to 100 , and the relative strength of each ODN was then calculated by the formula: Response to ODN - background

$$
\overline{\text { Maximum response - background }} \times 10,000
$$

aSignificantly greater than any other ODN $(\mathrm{P}<0.01)$.

A

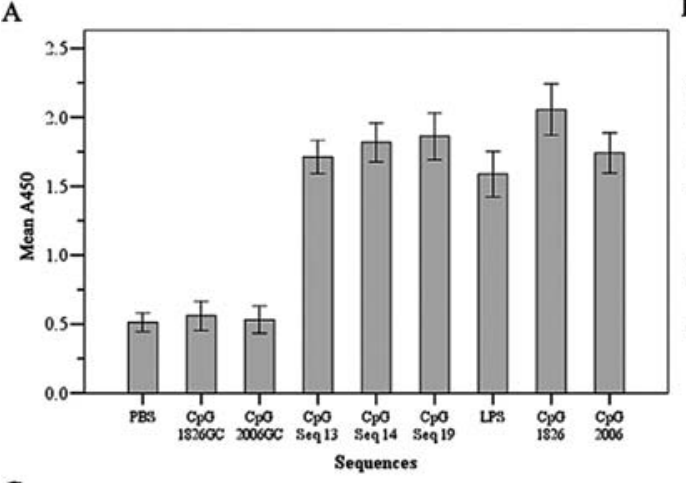

$\mathrm{C}$

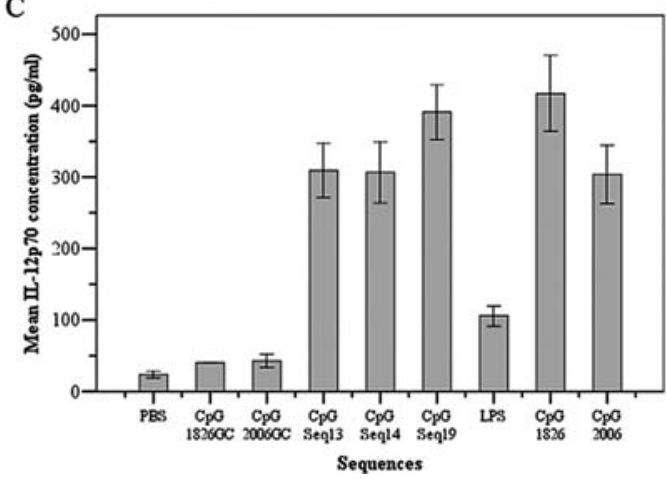

B

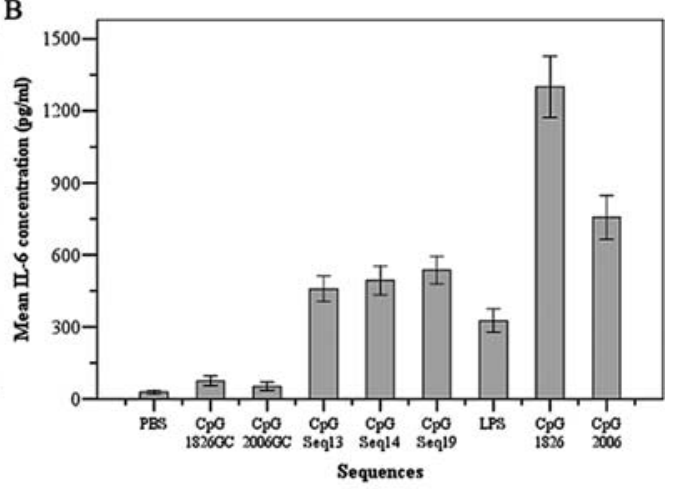

Figure 4. The immunostimulatory effects of CpG ODNs on mouse splenocytes. Peritoneal splenocytes $\left(5 \times 10^{5}\right)$ from Balb/c mice were treated with or without $1 \mu \mathrm{g} / \mathrm{ml}$ of CpG ODNs for $48 \mathrm{~h}$. The proliferation (A) of the splenocytes, as well as the secretion of IL-6 (B) and IL-12p70 (C), was determined. All tests were duplicated. Error bars indicate standard deviation. 
A

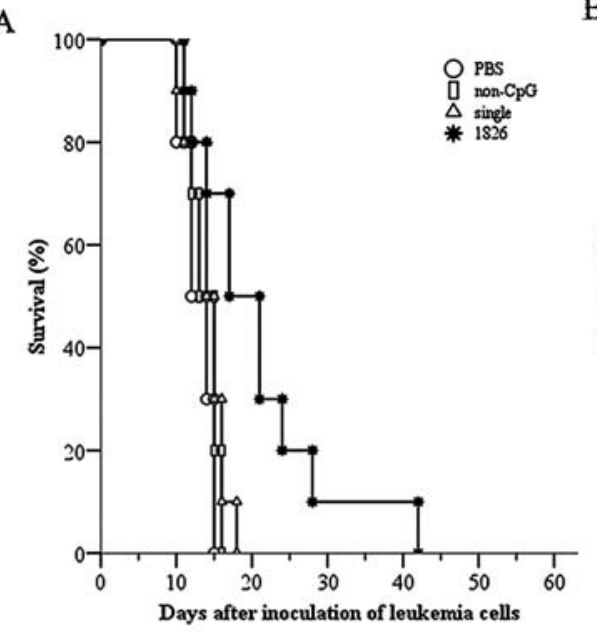

C

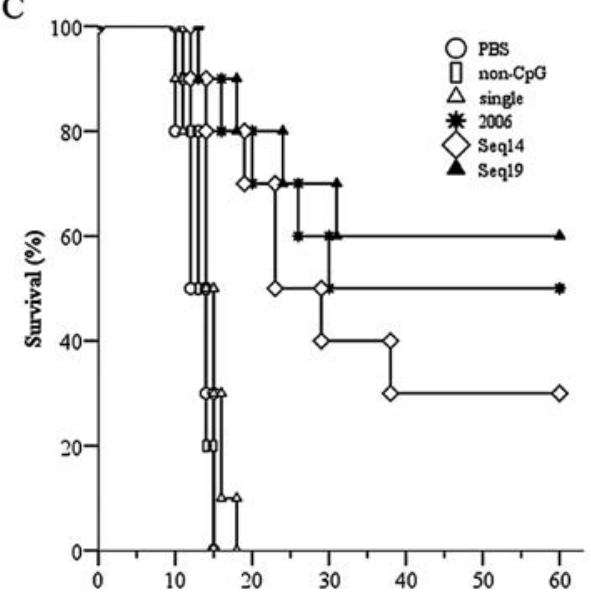

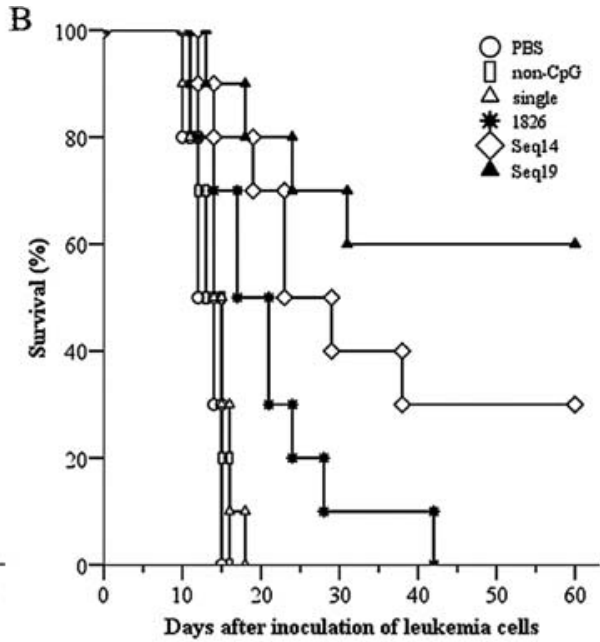

Figure 5. Injection of vaccines with or without CpG ODNs induces significant survival prolonging effects in DBA/2 mouse model. (A) The optimal mouse CpG ODN (CpG 1826) significantly improved the life-span compared to the single group only vaccinated with inactivated L1210 cells. Non-CpG here refers to $\mathrm{CpG} 1826 \mathrm{GC}$ as the ODN backbone control. (B) CpG Seq 14 and 19 compare to CpG 2006, which is optimal for humans. Non-CpG here refers to CpG 2006GC as the ODN backbone control. (C) CpG Seq 14 and 19 compared to the mouse motif, CpG 1826. Non-CpG here refers to CpG $1826 \mathrm{GC}$. Analysis of each experiment yielded a value of $\mathrm{P}<0.05$.

In vivo anti-leukemic activity of $C p G$ ODNs in mice with acute leukemia. In order to investigate whether CpG ODNs with strong in vitro stimulatory effects on both humans and mice had detectable anti-leukemic activity in vivo, groups of syngeneic DBA/2 mice $(n=10)$ received $1 \times 10^{5}$ live L1210 cells on day 0 by i.p. injection. The active immunotherapy began the following day. Mice received the vaccines with or without $\mathrm{CpG}$ ODN adjuvants by subcutaneous injection. During the experiment, the leukemia-bearing mice were observed daily for survival for at least 60 days.

In our experiments, $\mathrm{CpG}$ ODNs conferred a longer survival span in the leukemia-bearing mice. As seen in Fig. 5, mice from the control group injected with PBS began to die on the 9th day after inoculation with live L1210 cells, and the median survival time (MST) was $12 \pm 1.3$ days. The single group injected with inactivated L1210 cells alone, whose MST was $14 \pm 1.3$ days, had no increase in survival time relative to the control group $(\mathrm{P}>0.01)$. The non- $\mathrm{CpG}$ group, used as the control ODN, did not present an improvement of life-span compared to that of either the control or single groups $(\mathrm{P}>0.01)$. However, the MST of animals treated with CpG 1826 as the vaccine adjuvant was prolonged to $17 \pm 12.8$ days, which was significantly improved when compared to that of the other groups $(\mathrm{P}<0.01)$. Furthermore, the MST of the CpG 2006 group was as long as 30 days, and $50 \%$ of the mice survived for $>60$ days. Specifically, the long-term survival rate for mice treated with $\mathrm{CpG} 2006$ was $50 \%$. Above all, vaccines containing CpG Seq 14 or 19 showed surprisingly strong activity in prolonging survival span compared to the single group $(\mathrm{P}<0.001)$. The activity of both CpG Seq 14 and 19 was comparable to that of the CpG 2006 group, and that of the $\mathrm{CpG}$ Seq 19 group was even higher than that of the $\mathrm{CpG} 1826$ group $(\mathrm{P}<0.01)$. Although the $\mathrm{CpG}$ Seq 14 group showed a moderate increase in survival span compared to the $\mathrm{CpG} 1826$ group, there was no statistical difference. However, $40 \%$ of the mice survived long-term in the CpG Seq 14 group, while all the mice from the CpG 1826 group died before the 60th day after inoculation.

Potent anti-leukemic activity of CpG ODN with enhanced NK cell and CTL cytotoxicity. In order to examine the mechanism underlying the anti-leukemic effect of the vaccine with $\mathrm{CpG}$ ODN adjuvants, DBA/2 mice were inoculated by i.p. injectin with $1 \times 10^{5}$ live L1210 cells. The same treatment was given 

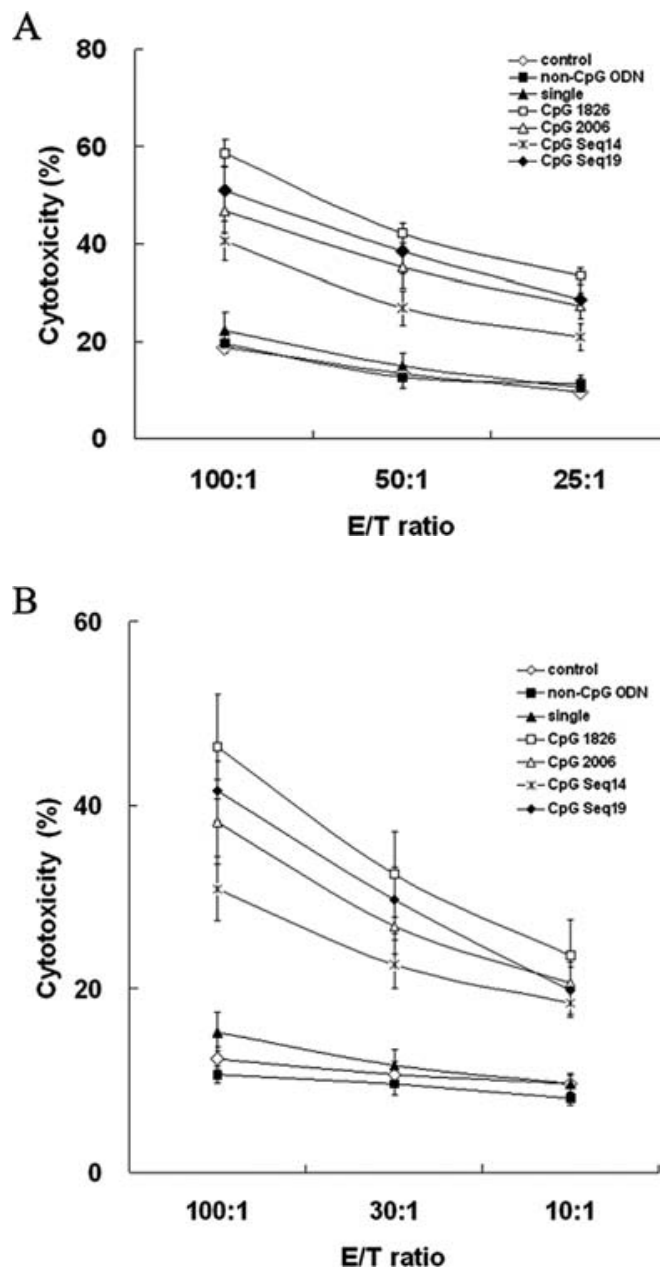

Figure 6. CpG ODN vaccination enhanced both the NK and CTL activities. (A) Splenocytes isolated from tumor-bearing mice were used in NK cytolytic assays E/T ratios of 100:1, 50:1 and 25:1. (B) Splenic lymphocytes of tumorbearing mice from different groups were prepared as previously described and wer then collected as CTL effector cells. L1210 cells were used as the target cells. The tumor-specific CTL cytotoxicity was determined at E/T ratios of 100:1, 30:1 and 10:1. Both the NK and CTL cytotoxicities were determined by a standard LDH release assay.

as described previously. Fourteen days after inoculation, the leukemia-bearing mice from the different groups were all sacrificed and the splenocytes were isolated to be used in cytolytic assays against YAC-1 cells by a standard LDH release assay. As shown in Fig. 6A, the NK activity of lymphocytes from mice treated with tumor vaccine containing CpG ODNs was significantly higher than that of the mice from the control or non-CpG groups $(\mathrm{P}<0.01)$. The $\mathrm{CpG}$ 1826 group showed the highest $\mathrm{NK}$ lysis activity at each $\mathrm{E} / \mathrm{T}$ ratio among these $\mathrm{CpG}$ ODN-treated groups $(\mathrm{P}<0.01)$. As for the CpG Seq14 and 19 groups, there was no significant difference between them, and both of them were similar to the CpG 2006 group (P>0.01) concerning NK activity.

Moreover, specific CTL cytotoxicity was observed in the isolated splenocytes after they were co-cultured with inactivated L1210 cells for 5 days in the presence of recombinant murine IL-2 $(20 \mathrm{U} / \mathrm{ml})$, and were then collected as CTL effector cells and the L1210 cells were used as the target cells. As seen in Fig. 6B, the specific CTL cytotoxicity of mice from the control group was on the base line, and there was no significant difference between the single and non$\mathrm{CpG}$ groups. This suggests that tumor antigens alone cannot induce effective specific CTL cytotoxicity. The splenic CTL activity of mice treated with $\mathrm{CpG}$ ODN plus inactivated L1210 cells was higher than that of the groups treated with PBS or inactivated L1210 cells alone $(\mathrm{P}<0.01)$. The highest CTL activity was induced in the $\mathrm{CpG}$ 1826-treated group in comparison to the other groups $(\mathrm{P}<0.01)$. There was no significant difference between the CpG Seq19 and CpG 2006 group in CTL activity. However, the activity of the $\mathrm{CpG}$ Seq14 group was lower than that in the groups treated with other stimulatory $\mathrm{CpG}$ ODNs $(\mathrm{P}<0.01)$. This suggests that specific anti-leukemic responses are significantly enhanced by the addition of CpG ODN adjuvants.

\section{Discussion}

CpG motifs are highly specific in receptor recognition, and therefore, even a single base difference also impacts the magnitude of the resulting immune response, and subsequently influences their anti-tumor activity. A CpG motif, consists of an unmethylated $\mathrm{CG}$ dinucleotide within certain neighboring nucleobases, and is considered to be an essential element responsible for the immunostimulatory effects of bacterial DNA and synthetic ODNs, especially the unmethylated CG dinucleotide. The immune activity of $\mathrm{CpG}$ ODNs is completely lost if CG dinucleotides are deleted or methylated. In this study, the control non-CpG sequences, CpG 2006GC and CpG 1826GC, with transversion of CG to GC, did not show apparent activity. Aside from the essential element, other factors also contribute to this activity, such as flanking bases, spacing, poly $\mathrm{G}$ ends, length, number of $\mathrm{CpG}$ motifs, and so on.

Early studies have indicated that the flanking bases of $\mathrm{CpG}$ dinucleotides play a significant role in modulating the level of immune activity of $\mathrm{CpG}$ ODNs. An optimal $\mathrm{CpG}$ ODN for B-cell activation was considered to contain a $\mathrm{CpG}$ motif in which the $\mathrm{CpG}$ dinucleotide was flanked by two $5^{\prime}$ purines (preferably a GpT or GpA dinucleotide) and two 3' pyrimidines (preferably a TpT dinucleotide) (25). It was then found that the exchange of the precise adenine on the 5 ' side of the $\mathrm{CpG}$ dinucleotide with thymidine, results in slightly higher activity, and the 6-mer motif, 5'-GTCGTT-3', has been demonstrated to be optimal in activating the human immune system (24). PF-3512676, containing three such potent motifs, has been widely used in clinical trials. Apart from the preferable 3'TpT dinucleotide, 3'TpC or TpA were also considered to be the formula of the most active B-class CpG ODN. However, our study shows that such replacement of the flanking bases (CpG Seqs 1-7, replace 3'TpT with $3^{\prime} \mathrm{TpC}$ or 3 'TpA) leads to a significant reduction in immunostimulatory activity when compared to $\mathrm{CpG} 2006$. In addition, there were no significant differences between CpG Seq 3 and 6, CpG Seq 2 and 5 and CpG Seq 1 and 4 as shown by lymphocyte proliferation assay and the cytokine secretion test. The two flanking sequences made equivalent contributions to the activity of the $\mathrm{CpG}$ motif, yet their roles were less significant than that of 3'TpT. Of note, is the fact that the activity of $\mathrm{CpG}$ Seq 7 was markedly stronger than that of 
both CpG Seq 2 and 4 with the same level of substitution (they all had two 3'TpT replaced). Structurally, CpG Seq 7 contains three different motifs (5'-GTCGTT-3', 5'-GTCGTC-3' and 5-GTCGTA-3') formed by switching 3'TpT with TpC and TpA, which are the most notable characteristics. Therefore, we speculated that synthesized single ODNs containing multiple different $\mathrm{CpG}$ motifs could help to enhance the immune stimulating activity. Detailed studies of large numbers of normal donors have indicated that the response of PBMCs from different individuals to $\mathrm{CpG}$ stimulation is heterogeneous $(15,26)$. Also, mixtures containing three or more different $\mathrm{CpG}$ ODNs have been shown to be capable of activating immune cells from virtually all donors, and maximizing the immune response (27). Therefore, we hypothesized that complex ODNs containing multiple different $\mathrm{CpG}$ motifs could play the same role in activating a heterogeneous population.

In addition to the bases adjacent to the $\mathrm{CpG}$ dinucleotides, we wished to determine whether other more distal sequences in ODNs could also modulate the stimulatory effect. Specifically, poly G runs, consisting of 4-6 Gs, have previously been reported to increase the immunostimulatory activity of PE ODNs (17-19). The location of the poly G motif within ODNs also affects their ability to uptake CpG ODNs, and the 3 '-end location proved to be better than the 5'-end. However, in our study, the addition of the 3'-poly G end to PTO-ODNs did not increase their immune activity. Instead, in certain sequences such as CpG Seq 12, the immunostimulation reduced, which was completely different from that of PE ODNs. The mechanisms of this are not quite clear. According to previous studies, poly $\mathrm{G}$ additions cause ODNs to be taken up more efficiently, and enhanced cellular uptake also results in increased immunostimulation correlated with increased IL-6 secretion and PBMC proliferation (18). However, the poly $G$ string only increased the cellular uptake of the otherwise weak incorporated PE-ODNs, and yet was unable to additionally increase that of PTO-ODNs, which were already being taken up very efficiently and are resistant to enzymatic degradation. It has also been observed that TLR9 cells transfected with high concentrations of PTO-poly G ODNs, are still less effective. Thus, it could be speculated that poly $\mathrm{G}$ strings are beneficial for cellular internalization, although they interfere with subsequent signal induction (28). Our data also support the previous opinion that poly G motifs can exert suppressive or stimulating effects on the immunostimulatory activity of $\mathrm{CpG}$ ODNs according to the modification of the ODN backbone.

Spacing sequences between individual $\mathrm{CpG}$ motifs also contribute to the immunostimulatory activity of CpG ODNs, and the separation by TpT is preferable (CpG 2006) (15). In this study, we found that deletion of the $\mathrm{T}$ spacing adjacent to the 5'-end lead to a significantly reduced immune activity of CpG ODNs. However, that of the 3'-end TpT spacing did not have such an effect. CpG Seqs 15 and 20, with T spacing adjacent to the 5 '-end deleted, showed a significant decrease in IL-6 / IL-12 secretion and PBMC proliferation. Moreover, CpG Seqs 16-19, with both the 5' and 3'-end T spacing deleted, showed markly decreased activity except for $\mathrm{CpG}$ Seq 19. However, CpG Seq 13 and 14, with T spacing adjacent to the 3 '-end partly deleted, showed similar activity to their prototype, $\mathrm{CpG}$ 2006. Taking into account the results from a previous study that the CpG ODN bind to TLR9 is closely related to their 5'-end, we inferred that the deletion of the 5'-end $\mathrm{T}$ spacing changes the 5'-end structure of $\mathrm{CpG}$ ODN, and subsequently interferes with the affinity between CpG ODN and TLR9, thus decreasing the immunostimulatory activity. However, to our surprise, CpG Seq 19 proved to be an exception. This sequence showed stronger immunostimulation than all the other CpG ODNs with $\mathrm{T}$ spacing deleted and was equivalent to $\mathrm{CpG}$ 2006. The mechanisms of this are unclear. The most distinguishing feature of CpG Seq 19 compared to $\mathrm{CpG} 2006$ is the deletion of one thymidine in the $\mathrm{T}$ spacing sequence of both the $5^{\prime}$ and 3 '-ends, respectively, which makes this ODN more symmetrical in structure than other $\mathrm{CpG}$ ODNs with one or more thymidines deleted. We speculated that the structural symmetry could have a beneficial effect for the CpG ODN on binding to its receptor, TLR9, and that it could offset the negative impact caused by the deletion of the 5 '-end $\mathrm{T}$ spacing on ligand binding to a certain extent.

Acute leukemia is a common malignant disease in clinical practice. Despite the development of a myriad of novel therapies, a large number of patients afflicted with this disease, still succumb to it. Therapeutic interventions with measurable and sustainable anti-tumor effects are required. Immunotherapy represents such an intervention. Conventional allogeneic bone marrow transplantation has proven to be the most effective immunotherapy. The graft-versus-leukemia effect observed after allogeneic stem cell transplantation, suggests that an effective immune response can cure acute leukemia, but the application is limited by its toxicity and the difficulty of finding suitable donors. Therefore, vaccination strategy has considerable appeal. The leukemia vaccine has shown specific anti-leukemic effect and lower toxicity as has previously been observed. Antigens in the vaccine formula determine the specificity of anti-tumor immune response. In previous studies, we investigated and indentified a type of leukemia-associated antigen in acute monocytic leukemia (29). However, tumor antigens alone may not be able to elicit effective specific anti-leukemic immunity, as leukemic blasts develop various escape mechanisms. In this study, all mice in the single group treated with inactivated L1210 cells alone died by the 18th day after i.p. inoculation with live L1210 cells. The MST (14 \pm 1.3 days) was not significantly prolonged compared to the control group ( $12 \pm 1.3$ days) treated with PBS buffer, neither was the CTL cytotoxicity, although we used whole tumor cells as the antigen source to maximally maintain the spectrum of tumor antigens. An appropriate adjuvant could help to improve the immunogenicity of tumor antigens, break the immune tolerance in leukemia patients, and thereby enhance the efficacy of the tumor vaccination. Examples of adjuvants are the granulocyte-monocyte colonystimulating factor and Freund's adjuvant, effective cytokines such as IL-12, and synthetic oligonucleotides comprising the $\mathrm{CpG}$ motif. Synthetic ODNs containing $\mathrm{CpG}$ motifs are excellent candidates for the combined treatment with tumor vaccines $(30,31)$, and many studies have shown that they can also enhance adaptive immunity for monotherapy (32).

The L1210 murine lymphoid leukemia cells are highly aggressive. The i.p. injection of $1 \times 10^{5}$ cells can cause death 
of all mice within 16 days. As few as $1 \times 10^{2}$ L1210 cells result in uniform mortality within 32 days. Mice that survive for $>60$ days after inoculation of L1210 cells could be regarded as long-term survivors (33). Our data showed that, compared to the control group, inactivated L1210 cells did not significantly prolong the survival span of mice, most likely due to their poor immunogenicity. However, the therapeutic effect was greatly enhanced by the $\mathrm{CpG}$ ODN adjuvant. The survival time of $\mathrm{CpG}$ ODN-treated mice was markedly prolonged, and $30-60 \%$ of mice achieved long-term survival. This suggests that the immunostimulatory $\mathrm{CpG}$ ODN adjuvant could act in synergy with tumor antigens to elicit a functional anti-leukemic effect and induce the immune protection against progressive leukemia.

Further studies on NK cytotoxicity and CTL activity for the uncovering of the immune mechanism, also support this result. In our present study, markedly elevated CTL activity against L1210 was observed in mice treated with the $\mathrm{CpG}$ ODN adjuvant compared to the single and control groups, which is in agreement with the survival time of mice. The potent CTL responses of the $\mathrm{CpG}$ ODN-treated mice strongly suggest that the leukemia vaccine containing the CpG ODN adjuvant induces specific anti-leukemic activity and effective immune protection with regressed ascites and prolonged survival span. The mechanism of enhanced CTL activity could be attributed to the antigen presentation being changed by $\mathrm{CpG}$ ODN activation. As far as we know, $\mathrm{CpG}$ ODN functions through the activation of TLR9 which is expressed mainly in B-cells and dendritic cells in humans. Both of these cells play an important role in antigen presenting, especially the dendritic cells. The activation of TLR9 leads to a Th1like cytokine and chemokine environment, then it activates dendritic cells and up-regulates the expression of the costimulatory molecules in plasmacytoid dendritic cells (pDCs). The required co-stimulatory signals for $\mathrm{T}$ cell activation are provided, then $\mathrm{T}$ cells are shifted in response to tolerance and this results in enhanced CTL activity. If there is no TLR9 activation, tumor antigens are presented by immature dendritic cells, which create an environment that favors the maintenance of $\mathrm{T}$ cell tolerance, preventing the development of anti-tumor immunity. Apart from the specific anti-leukemic CTL response, we found that NK cells were also critical in the rejection of leukemia, and markedly augmented NK cell cytotoxicity was observed in mice injected with CpG ODNs, suggesting that non-specific immunity could be involved in the anti-leukemic responses of the active immunotherapy of the leukemia vaccine. On the whole, the vaccine containing the $\mathrm{CpG}$ ODN adjuvant has a strong in vivo anti-leukemic activity with augmented NK and CTL activity.

CpG ODN is considered safe and well tolerated in comparison to many other adjuvants, as previously described (34). The most common side-effects are mild to moderate injection-site reactions and transient flu-like symptoms. As we found in our study, all injections were safe and very well tolerated. There were no ulcerations, granulomas, or other injection site abnormalities. However, we found that some mice in the $\mathrm{CpG}$ 1826-treated group showed progressive weight loss and reduced motoricity after being injected and all mice died despite regressed ascites. Nevertheless, both the
NK and CTL activities in this group were much stronger than those in any other group. This indicates that $\mathrm{CpG} 1826$ induces the most potent innate and adaptive anti-leukemic response in vivo, despite of no long-time survival in this group. We speculated that this phenomenon was most likely related to the excessive immune response induced by $\mathrm{CpG}$ 1826. As earlier studies have shown, rodents respond with high serum concentrations of pro-inflammatory cytokines, such as TNF- $\alpha$, to $\mathrm{CpG}$ ODN administration, which can result in a lethal 'cytokine storm' (35). However, there was no change in serum TNF- $\alpha$ levels following CpG injection in humans and primates (36), suggesting that $\mathrm{CpG}$ ODN should be safe for and well tolerated by humans. This is possibly related to the different cellular distributions of TLR9 between primates and rodents. TLR9 is limitedly expressed in B-cells and pDCs in humans, whereas the opposite occurs in mice, monocytes, and possibly all DC subsets $(37,38)$. As TLR9 is expressed in a broader range of immune cells in rodents, the immune responses could be more intense and broader than those in primates. Therefore, mice tend to be more susceptible to toxicities as opposed to primates. Moreover, we also found that mice treated with CpG 2006, CpG Seq 14 and 19, displayed less damage in the spleen and liver when compared to the CpG 1826-treated mice (data not shown). The reason for this could be the species-specific differences in the optimal $\mathrm{CpG}$ sequences for potency. The 6-mer motif, 5'-GACGTT-3', is considered to be the optimal CpG motif for rodents (39). For example, CpG 1826 containing the 5'-GACGTT-3' motif is potent in inducing immunostimulatory effects in mice. Whereas the 5'-GTC GTT-3' motif in CpG 2006, CpG Seq 14 and 19, represents the optimal $\mathrm{CpG}$ motif for primates (15), in mice, most of its potency in $\mathrm{CpG} 1826$ is relatively weaker. As we observed in this study, these CpG ODN sequences showed good tolerance and no obvious immunotoxicity.

In conclusion, these data indicate that structural characteristics of immunostimulatory $\mathrm{CpG}$ ODNs, such as flanking bases, spacing, poly $\mathrm{G}$ ends, length, number of $\mathrm{CpG}$ motifs and so on, have a significant impact on their activity. These findings have important implications for the rational design of B-class ODNs. We then selected several $\mathrm{CpG}$ ODNs with high activity in human and mouse immune cells and used them as immune adjuvants, thus demonstrating that CpG ODNs are active against the highly malignant L1210 leukemia mouse model via innate and adaptive immune augmentation. Among the $\mathrm{CpG}$ ODN-treated groups, $\mathrm{CpG}$ Seq 19 led to the best therapeutic effect, with $60 \%$ of mice achieving long-term survival. The long-term survival of mice in the $\mathrm{CpG}$ Seq 14 group was $30 \%$. The effective antileukemic activity validates these in vitro observations. Given the high efficiency and low toxicity, we believe that CpG Seq 14 and 19 could be applied in pre-clinical and clinical studies for the immunotherapy of acute leukemia. Towards improving the therapeutic efficacy of $\mathrm{CpG}$ ODN, further studies are currently underway.

\section{Acknowledgements}

We are grateful for the financial support from the National Natural Science Foundation of China (grant no. 30570775). 


\section{References}

1. Zhang WG, Liu SH, Cao XM, et al: A phase-I clinical trial of active immunotherapy for acute leukemia using inactivated autologous leukemia cells mixed with IL-2, GM-CSF, and IL-6. Leuk Res 29: 3-9, 2005.

2. Rosenberg SA, Yang JC, Schwartzentruber DJ, et al: Immunologic and therapeutic evaluation of a synthetic peptide vaccine for the treatment of patients with metastatic melanoma. Nat Med 4: 321-327, 1998.

3. Toes RE, Offringa R, Blom RJ, Melief CJ and Kast WM: Peptide vaccination can lead to enhanced tumor growth through specific T-cell tolerance induction. Proc Natl Acad Sci USA 93: 7855-7860, 1996.

4. Speiser DE, Lienard D, Rufer N, et al: Rapid and strong human $\mathrm{CD}^{8+} \mathrm{T}$ cell responses to vaccination with peptide, IFA, and CpG oligodeoxynucleotide 7909. J Clin Invest 115: 739-746, 2005.

5. Krieg AM: CpG motifs in bacterial DNA and their immune effects. Annu Rev Immunol 20: 709-760, 2002.

6. Brazolot Millan CL, Weeratna R, Krieg AM, Siegrist CA and Davis HL: CpG DNA can induce strong Th1 humoral and cellmediated immune responses against hepatitis B surface antigen in young mice. Proc Natl Acad Sci USA 95: 15553-15558, 1998.

7. Corral RS and Petray PB: CpG DNA as a Th1-promoting adjuvant in immunization against Trypanosoma cruzi. Vaccine 19: $234-242,2000$

8. Zhang Y, Palmer GH, Abbott JR, Howard CJ, Hope JC and Brown WC: CpG ODN 2006 and IL-12 are comparable for priming Th1 lymphocyte and IgG responses in cattle immunized with a rickettsial outer membrane protein in alum. Vaccine 21 : 3307-3318, 2003.

9. Klinman DM: Immunotherapeutic uses of $\mathrm{CpG}$ oligodeoxynucleotides. Nat Rev Immunol 4: 249-258, 2004.

10. Verthelyi D and Klinman DM: Immunoregulatory activity of $\mathrm{CpG}$ oligonucleotides in humans and nonhuman primates. Clin Immunol 109: 64-71, 2003.

11. Leonard JP, Link BK, Emmanouilides C, et al: Phase I trial of toll-like receptor 9 agonist PF-3512676 with and following rituximab in patients with recurrent indolent and aggressive non Hodgkin's lymphoma. Clin Cancer Res 13: 6168-6174, 2007.

12. Rayburn ER, Wang W, Zhang R and Wang H: Experimental therapy for colon cancer: Anti-cancer effects of TLR9 agonism, combination with other therapeutic modalities, and dependence upon p53. Int J Oncol 30: 1511-1519, 2007.

13. Hegele A, Dalpke A, Barth P, et al: Antineoplastic effect of immunostimulatory DNA (CpG-ODN) in a murine C57-BL6/ MB-49 transitional cell carcinoma model. Anticancer Res 24: 2225-2230, 2004.

14. Carpentier A, Laigle-Donadey F, Zohar S, et al: Phase 1 trial of a $\mathrm{CpG}$ oligodeoxynucleotide for patients with recurrent glioblastoma. Neuro Oncol 8: 60-66, 2006.

15. Hartmann G, Weeratna RD, Ballas ZK, et al: Delineation of a $\mathrm{CpG}$ phosphorothioate oligodeoxynucleotide for activating primate immune responses in vitro and in vivo. J Immunol 164: $1617-1624,2000$.

16. Hartmann G, Krug A, Eigler A, et al: Specific suppression of human tumor necrosis factor-alpha synthesis by antisense oligodeoxynucleotides. Antisense Nucleic Acid Drug Dev 6: 291-299, 1996

17. Zhang Z, Guo K and Schluesener HJ: The immunostimulatory activity of $\mathrm{CpG}$ oligonucleotides on microglial N9 cells is affected by a polyguanosine motif. J Neuroimmunol 161: 68-77, 2005.

18. Bartz H, Mendoza Y, Gebker M, Fischborn T, Heeg K and Dalpke A: Poly-guanosine strings improve cellular uptake and stimulatory activity of phosphodiester $\mathrm{CpG}$ oligonucleotides in human leukocytes. Vaccine 23: 148-155, 2004.

19. Zimmermann S, Heeg K and Dalpke A: Immunostimulatory DNA as adjuvant: efficacy of phosphodiester CpG oligonucleotides is enhanced by 3 ' sequence modifications. Vaccine 21: 990-995, 2003.
20. Davis HL, Weeratna R, Waldschmidt TJ, Tygrett L, Schorr J and Krieg AM: CpG DNA is a potent enhancer of specific immunity in mice immunized with recombinant hepatitis B surface antigen. J Immunol 160: 870-876, 1998.

21. Chu RS, Targoni OS, Krieg AM, Lehmann PV and Harding CV: CpG oligodeoxynucleotides act as adjuvants that switch on $\mathrm{T}$ helper 1 (Th1) immunity. J Exp Med 186: 1623-1631, 1997.

22. Lipford GB, Bauer M, Blank C, Reiter R, Wagner H and Heeg K: CpG-containing synthetic oligonucleotides promote $\mathrm{B}$ and cytotoxic $\mathrm{T}$ cell responses to protein antigen: a new class of vaccine adjuvants. Eur J Immunol 27: 2340-2344, 1997.

23. Weiner GJ, Liu HM, Wooldridge JE, Dahle CE and Krieg AM: Immunostimulatory oligodeoxynucleotides containing the $\mathrm{CpG}$ motif are effective as immune adjuvants in tumor antigen immunization. Proc Natl Acad Sci USA 94: 10833-10837, 1997.

24. Hartmann G and Krieg AM: Mechanism and function of a newly identified CpG DNA motif in human primary B cells. J Immunol 164: 944-953, 2000.

25. Krieg AM, Yi AK, Matson S, et al: CpG motifs in bacterial DNA trigger direct B-cell activation. Nature 374: 546-549, 1995.

26. Bohle B, Orel L, Kraft D and Ebner C: Oligodeoxynucleotides containing $\mathrm{CpG}$ motifs induce low levels of TNF-alpha in human B lymphocytes: possible adjuvants for Th1 responses. J Immunol 166: 3743-3748, 2001

27. Klinman DM, Currie D, Gursel I and Verthelyi D: Use of CpG oligodeoxynucleotides as immune adjuvants. Immunol Rev 199: 201-216, 2004

28. Dalpke AH, Zimmermann S, Albrecht I and Heeg K: Phosphodiester $\mathrm{CpG}$ oligonucleotides as adjuvants: polyguanosine runs enhance cellular uptake and improve immunostimulative activity of phosphodiester $\mathrm{CpG}$ oligonucleotides in vitro and in vivo. Immunology 106: 102-112, 2002.

29. Zhang P, Zhang W, He A, Wang J and Li W: Identification and functional characterization of the novel acute monocytic leukemia associated antigen MLAA-34. Cancer Immunol Immunother 58: 281-290, 2009.

30. Davila E, Kennedy R and Celis E: Generation of antitumor immunity by cytotoxic $\mathrm{T}$ lymphocyte epitope peptide vaccination, CpG-oligodeoxynucleotide adjuvant, and CTLA-4 blockade. Cancer Res 63: 3281-3288, 2003.

31. Wu A, Oh S, Gharagozlou S, et al: In vivo vaccination with tumor cell lysate plus $\mathrm{CpG}$ oligodeoxynucleotides eradicates murine glioblastoma. J Immunother 30: 789-797, 2007.

32. Cho HC, Kim BH, Kim K, Park JY, Chang JH and Kim SK: Cancer immunotherapeutic effects of novel CpG ODN in murine tumor model. Int Immunopharmacol 8: 1401-1407, 2008.

33. Zhang B, Wu KF, Lin YM, et al: Gene transfer of pro-IL-18 and IL-1 beta converting enzyme cDNA induces potent antitumor effects in L1210 cells. Leukemia 18: 817-825, 2004.

34. Cooper CL, Davis HL, Morris ML, et al: Safety and immunogenicity of CPG 7909 injection as an adjuvant to Fluarix influenza vaccine. Vaccine 22: 3136-3143, 2004.

35. Sparwasser T, Miethke T, Lipford G, et al: Bacterial DNA causes septic shock. Nature 386: 336-337, 1997.

36. Krieg AM, Efler SM, Wittpoth M, Al Adhami MJ and Davis HL: Induction of systemic TH1-like innate immunity in normal volunteers following subcutaneous but not intravenous administration of CPG 7909, a synthetic B-class CpG oligodeoxynucleotide TLR9 agonist. J Immunother 27: 460-471, 2004.

37. Liu YJ: IPC: professional type 1 interferon-producing cells and plasmacytoid dendritic cell precursors. Annu Rev Immunol 23: 275-306, 2005

38. Iwasaki A and Medzhitov R: Toll-like receptor control of the adaptive immune responses. Nat Immunol 5: 987-995, 2004.

39. Yi AK, Chang M, Peckham DW, Krieg AM and Ashman RF: CpG oligodeoxyribonucleotides rescue mature spleen B cells from spontaneous apoptosis and promote cell cycle entry. J Immunol 160: 5898-5906, 1998. 